Proceedings of the 50th Hawaii International Conference on System Sciences | 2017

\title{
Information Uses and Learning Outcomes During Guided Discovery in a Blended E-Learning Game Design Program for Secondary Computer Science Education
}

\author{
Rebecca Reynolds \\ Rutgers University \\ School of Communication \& Information \\ rebecca.reynolds@rutgers.edu
}

\author{
Christopher Leeder \\ Rutgers University \\ School of Communication \& Information \\ cal293@scarletmail.rutgers.edu
}

\begin{abstract}
This study investigates middle school and high school students' online information uses and social constructivist engagement during a blended e-learning program of game design for computer science education. Students use a learning management system (LMS) pre-populated with curriculum and resources, participating in an in-school class, daily for credit and a grade for a year, with non-expert teachers. This blended e-learning model aims to contribute to scaling of CS education, towards meeting the needs of teacher shortages in this domain. The study draws on Google Analytics data to describe student activity patterns and investigate relationships between measured patterns and learning outcomes. Findings show two activity factors emerging in student resource uses (less advanced, more advanced), and correlations between uses of more advanced resource, and outcomes. Further, student uses of the "team page," the locus of their social constructivist game design engagement online, are highly correlated with outcomes. The research offers some support for effectiveness of such blended learning approaches in supporting CS education in this age group through knowledgebuilding, while also showing areas for improvement in instructional design, including direct scaffolding of information literacy instruction in such contexts.
\end{abstract}

\section{Introduction}

A national call to action has been issued in education policy, to offer more computer science (CS) opportunities in the lower grade levels [1],[2]). Game design has been described and studied as a high potential approach for cultivating CS knowledge and computational thinking (CT) as well as STEM subject area learning such as math or science in younger learners (e.g., [3], [4]). In summarizing the state of the computational thinking arena, Grover and Pea [5] note that game design is "ideal not only for motivating and engaging school children but for introducing them to computer science," offering a means for active student exploration of CT. Unlike traditional CS curriculum, which has tended to focus on principles-first learning of CS (not situated in a context), game design offers the opportunity for project-first learning -- a more engaging way to introduce CS [3]. One key challenge in realizing the goals of CS and CT education in K-12, though, is the scarcity of secondary school educators who are trained to teach these subjects [1].

Given the challenge of teacher scarcity, curriculum that instead relies on expertise integrated into systems may be one workaround, at least in the present timeframe. Learning management system (LMS) content publishing platforms produced by commercial technology vendors are ubiquitous in higher education [6] and growing in use in middle school and high schools. Understanding how these systems can support discovery-based learning processes for CS and CT education is becoming an increasingly important research question.

This study considers ways in which middle school and high school student uses of a game design curriculum offered via an online LMS contribute to guided discovery-based learning of introductory game design and digital literacy development. In particular, this study focuses centrally on how LMS site metrics page view data can contribute to our understanding of the role of student resource use processes, towards game design and learning outcomes.

LMS platforms make available a rich resource of detailed click-level data on student actions that can be used as learning analytics [7]. Systems data offers behavioral metrics on actual resource uses. These learner-produced data trails provide researchers with structured representations of the learners' interaction within a system, and can be analyzed towards offering improvements to instruction [8]. The predictive power of such LMS data can also potentially be harnessed towards developing reporting tools on process-level phenomena, that can help moderators identify at-risk students, and aid in developing techniques to support their learning [9].

Limitations also exist, however, in establishing valid research findings and data management practices 
for schools and for curriculum providers. For instance, some datasets such as the one used in this study, are available at aggregate levels of analysis only, thereby masking insights on phenomena at lower levels. Research that considers what user phenomena such aggregate data actually represent, and, its limitations, is important as we continue developing the field of learning analytics.

This study draws upon site metrics data on student information resource uses indicating the frequency and type of student LMS resource uses, and the paper reports patterns of engagement within and across 20 schools. The study also addresses ways in which student actions on the LMS relate to their knowledge outcomes, as measured by reliable content analysis of their digital work products. The study addresses both opportunities and challenges presented when trace data are merged with other sources, and builds on our understanding of student engagement in guided discovery-based learning processes, when attempting to learn introductory CS education through an autonomy-supportive program of game design.

\section{Literature Review}

\subsection{Game design for learning CS and CT}

Game design approaches have been noted in the learning sciences research literature for their potential to support CS and CT knowledge development, as well as traditional school subjects like science and math, in that students can create games about topics and themes, building constructively on their classroom learning [3]. Ways of knowing in game design include systems-based thinking, interdisciplinary thinking, user-centered design, specialist language, meta-level reflection, network literacy, and productive/tool literacy [10]. Student social discourse around designing science games has been found to afford engagement and learning of science content [11]. Game design and other creative computational artifact production were found to enable learning and participation through the input of the individual, group collaboration, and the mediation of the shared artifact itself [12]. The National Science Foundation (NSF) has supported game design as one instructional design potential approach for addressing the need to expand the reach of CS and CT educational opportunities into US schools. For instance, Reppening, Webb and Ioannidou [4] developed a checklist for incorporating CT into public schools via game design.

\subsection{Blended learning and guided discovery- based learning approaches}

Blended learning is the implementation of formal learning interventions involving delivery of content and instruction via digital and online media, coupled with in-class face-to-face guidance and instruction by a teacher. Guided discovery-based "Constructionist" learning approaches are often offered in blended learning contexts, and involve students' independent inquiry and resource uses towards a project-based learning task. Such approaches can augment student engagement, autonomy, social relatedness and knowledge-building (e.g., [13]). However, in such autonomy-supportive approaches, the extent of structure provided plays a role in students' success. Less-structured interventions have been critiqued due to their potential to tax cognitive load, with the result of frustrating or demotivating students [14]. Given literature on cognitive load, we know that human thinking, learning and working memory in a given instance are finite; during the learning of discrete knowledge (such as a specific programming, math, or science concept or task), distraction, frustration and demotivation can occur when one is also faced with overly taxing inquiry and resource use requirements to find help solving the problem [14].

Adding further contrast within such debates, studies of moment-by-moment engagement and learning via educational video games have shown that the psychological states of frustration, arousal and anxiety are the most highly correlated with learning [15]. Furthermore, proponents of guided discovery assert that when the learning environment is semistructured by systems and/or expert guides, the process of inquiry supports greater autonomy among students, and such student-centered blended learning contexts can be more responsive to variations in student individual differences, offer self-pacing and student choice [13].

Thus, debates around structure and agency during guided discovery-based learning are evident in the literature. Pragmatically, given the challenge of teacher recruitment and infrequent $\mathrm{CS}$ education opportunities in US schools, blended guided discovery-based learning approaches offer potential in affording students and teachers with an organized curriculum and structured sources of expertise, for instance, via a prestocked LMS that are full of resources, curricula and activities designed by game design learning experts. Such systems have potential to mitigate some of the noted barriers to school and teacher change that Norris and Soloway [16] identify as lack of vision, lack of leadership, lack of money, curriculum, technical and human infrastructure, parents resisting $21 \mathrm{st}-$ Century methods, the long life cycle of educational change, and assessment. Given debates in the literature, however, we need to better understand how students interact with such systems, and how to optimize them to meet a greater diversity of student needs. 


\subsection{Constructionism and knowledge-building}

In this study we investigate how a guideddiscovery-based learning approach is used to teach introductory programming to middle schoolers through game design. The instruction was influenced by social constructivism [17] and Constructionism (e.g., 18]) and relates to knowledge-building. Constructionism is a teaching philosophy and framework for learning and educative action [19] that builds upon Vygotsky's [17] social constructivist theory and Piaget's constructivist theory. In Constructionist learning, students engage in conscious construction of a computational artifact in a workshop-style group educational environment [18]. This approach holds that individuals learn best when mobilizing their entire selves in a personally meaningful pursuit while sensing that their work is valued as part of a larger enterprise [20], [21]. Aligning with social constructivism, Constructionist interventions are designed to facilitate learners' building of knowledge socially through dialogue and social interaction with peers, experts, and the use of resources. Learners create a computational artifact through programming and learning environments are workshop-based, in-person, and offer both social affordances as well as significant time on task and time for students' alone reflection on their work [18].

The literature on "knowledge-building" (e.g., [22]) is related to Constructionism. In this approach, learning contexts are designed to facilitate students' building of theories and conceptual artifacts. A primary goal is to engage learners in sustained collaborative inquiry and provide them with opportunities to work creatively with ideas [23]. Students collaboratively construct ideas through discourse, in resolution of authentic problems [24]. Linkages have been made between Scardamalia's [22] twelve principles of knowledgebuilding and the instructional conditions of Constructionist interventions [25]. In Constructionism, the productive outcome comprises both conceptual and concrete computational artifacts, such as content posted on the LMS and a final digital product [25].

\subsection{Research questions}

The game design program we investigate applies the conditions described above. The curriculum in the 2012/2013 school year included affordances such as teacher professional development, support for student peer collaboration, and a "coordinating representation" [27] in the form of an online LMS. This e-learning system contained a sequence 4 learning units including assignments, activities, informational texts and video resources, as well as online social spaces supporting construction and creation). Students used these resources to support learning tasks, and were encouraged to develop game themes and messages through online research.

Salomon, Perkins \& Globerson [26] describe such a platform as a "coordinating representation," a type of scaffolding support in which "an intelligent technology that can undertake a significant part of the cognitive process." Larussen \& Alterman [27] found that online learning environments similar to the Globaloria LMS are effective in supporting project-based work, making it easier for actors to work in parallel, multitask and make 'common sense' of a situation and how to proceed with the action (p. 375).

Past qualitative research on six team cases from a single school who participated in this same intervention [28] reports ways in which students' varying tasks (such as game subject development, graphic design, and programming), lead to varying types of resource uses. Further Reynolds [28] reports that for the more difficult task of programming, students use the LMS tutorial information resources to a greater extent, but also experience challenge in using the resources to code game script. The study discusses additional instructional scaffolds that might improve outcomes, while highlighting how gaps in information literacy among today's middle school and high school students can hinder the potential promise and success of blended, guided discovery-based learning protocols, for introductory programming instruction [28].

In this study, using trace log data and site metrics data for a larger $\mathrm{N}$ of students, we consider ways in which specific feature affordances of the curriculum are utilized, and how these relate to learning outcomes. Patterns of resource uses are part and parcel of the Constructionist knowledge-building process. We expect that particular information resource use patterns may contribute more so to knowledge building processes and outcomes, than others. Therefore, this study explores two specific research questions.

1. To what extent do student uses of LMS resources vary by resource type, by school, and across time?

2. In what ways do students' uses of different types of information resources across time appear to be related to learning outcomes?

Addressing these questions offers insight into the ways in which certain features of guided discovery based elearning systems employing an online e-learning system (LMS) can be useful for teaching the challenging subject of introductory programming. Another question underscoring this work, is whether the literature on Constructionism and knowledgebuilding theoretical principles can inform our understanding of resource use patterns during guided discovery. We also consider how school-level variation in feature usage may come into play. The study also offers explication of the limitations in uses of data 
sources such as trace logs and Google Analytics page read metrics, aggregated at the school level of analysis.

\section{Methods}

\subsection{Intervention.}

Globaloria is a blended learning curricular solution offering guided discovery-based game design and programming learning experiences via a LMS. This study focuses on the 2012/2013 school year's implementation. The program continues to evolve each year, and features have changed as of this publication, including a greater focus of late on Java as the game design programming language.

In the 2012/2013 school year, students took a game design elective class daily, for credit and a grade, often adjacent to a math or science class, creating games with messages that extend curricular themes they are learning in class. Students used programming software such as HTML5 and Adobe Flash in that timeframe, to learn introductory coding and create a playable digital web game. The primary goal from the students' perspective is the successful completion of a functioning web game.

The program required teacher participation in professional development trainings, mentoring from master teachers, a teacher portal and LMS that has resources including assessments, rubrics, design templates, forums, and other guides, on-location and virtual instruction from industry experts, and a virtual help desk available during school hours, to scaffold student game design learning. Educators trained along side students in the first year to become expert in the overall model and the content area of game design and programming over time. All participants utilized the provided resources to learn collectively, and teacher

\section{Table 1. Outline of 2012/2013 Globaloria Game Design Curriculum}

\begin{tabular}{l} 
Intro: Home page, active classes page, game gallery \\
Unit 1: getting started: 5 activities included an overview, \\
exploring Globaloria, creating blog, getting online accounts \\
set up \\
Unit 2: game making intro: hidden object game: Included \\
8 activities for creating an initial simple intro level game. \\
Included playing sample prior year games, choosing a game \\
topic, creating prototype, learning introductory Flash \\
software and Actionscript programming features, including \\
buttons, drag and drop, scoring, and presenting intro game \\
Unit 3: game design: 16 activities included choosing team \\
game topic, developing a plan, prototypes, features in Flash \\
such as buttons, sound, animation, keyboard input, drag and \\
drop. File version control also a topic \\
\hline Unit 4: game development: 6 activities included updating \\
their development plan, pseudocode, commenting code, \\
testing and debugging, and presenting \\
Actionscript tutorials: 17 tutorials at more advanced levels \\
includes background music, collision detection, conditional \\
statements, enemy behaviour, movie clips, jumping and \\
platforms, etc.
\end{tabular}

expertise is meant to build with each new cohort.

The LMS was built upon MediaWiki architecture. Each participating school received a class account stocked with the curriculum resources, and individualized student and teacher member accounts. The LMS contained three types of features: (1) information resources including a sequence of 4 learning units and the numerous cumulative learning activities built in, video- and text-based tutorial resources, and worked examples of game design code; (2) project management features enabling uploading, sharing, and archiving of game artifacts; (3) editable pages including profile, project and team pages facilitating communication and collaboration. During the first two curriculum units, working as individuals, students learned introductory programming by creating and presenting a simplified "hidden object game" which teaches basic programming fundamentals. They then segued into teamwork in Units 3, choosing a more complex game idea in a particular genre such as a platform jumper game, adventure game or maze. Table 1 and Figure 1 highlight curriculum units of instruction, and a screenshot of a Unit 2 assignment.

This study draws upon Google Analytics page view data from the wiki-based LMS, for all full-year locations. Google Analytics is a web analytics service that tracks and reports website traffic, including actions of users while visiting a page. User activity is automatically recorded and displayed through dashboard visualizations and downloadable reports. A free version of Google Analytics is available for tracking basic data. The service is implemented by adding a custom tracking code directly into the HTML source code of each page of a website. For this study, page view data was gathered for every page in the project LMS.

\subsection{Participants}

Google Analytics page read data and game outcome scores were aggregated for a sample of students who participated in the game design, during 2012-2013. The data collected represents user actions for a total of 625

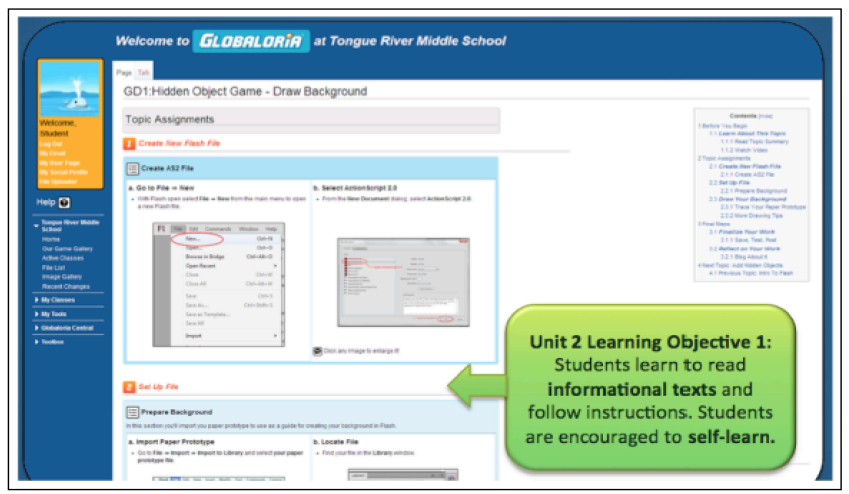

Figure 1. 2012/2013 Globaloria Curriculum: Screenshot of Unit 2, learning objective 1, and adjacent information resources 
students in grades 6-12 in 23 public schools (3 California, 20 West Virginia), who participated for a year. Students created a total of 214 games. At three schools only a small number of students created final games, and we found that they either had a teacher turnover, or events during the year that intervened in the program's full completion, such as a change in availability of lab space or a shift / reduction / removal of time in the block schedule for full program implementation. While this is fairly rare, such shifts in school administrators' priorities sometimes occurs mid-stream in schools. The program staff works extensively to accommodate schools' partial implementation with ongoing supports. We omitted these 3 schools from our descriptive tables and bivariate analyses as they fell short of our criteria for "full implementation," thus yielding a dataset of 20 schools, 488 students and 207 total games.

\subsection{Data Source Description, Dataset 1}

Page view reports were run by school, in aggregate, and across 5 time increments: 8/01/2012-9/30/12; $10 / 01 / 2012-11 / 30 / 12 ; 12 / 01 / 2012-1 / 31 / 13 ; 2 / 01 / 2013$ $03 / 31 / 13$; 4/01/2013-6/25/13. We exported the data from Google Analytics as Excel files for each school, into a master spreadsheet. We calculated standardized metrics, dividing total page views by the $\mathrm{N}$ of student participants at that location for any given resource, to calculate average page views / student / year for the given resource.

Editable student pages. In the 2012/2013 curriculum, Profile pages are those pages editable by students, on which students post images and information about themselves to create an initial online identity. Profile pages do not contain game files or game work. Project pages are those pages editable by students, on which students post their individual-level hidden object game files and game design work from the first half of the school year. In contrast, Team pages are those pages editable by all members of student teams, which serve as the locus of team activity, where they post shared game files, design plans, and text-based communications and discussions about the ongoing progress of their game.

Information Resources. In the 2012/2013 curriculum, curriculum unit pages (Table 1) are not editable by students, and contain curriculum content, assignments, tutorials, and instructions, video and sample code to support game design learning. The Intro unit contains the Game Gallery, featuring all past completed games in Globaloria. During the Intro and Unit 1 activities, students are introduced to game design as a concept, set up their accounts, profile pages, project pages and begin to brainstorm a game topic. During Unit 2, they create a hidden object-game in which they are introduced to initial programming functions. During Units 3-4, students work on a more advanced team game, in which they must collaborate to establish game concepts, delegate tasks, develop the game assets and program the game code, combining all files into a single, final functioning interactive web game by the end. In 2012/2013, students used Flash software, posting iterative versions of their game files in the online course LMS, documenting their work and constructing ongoing iterations. The final activities in Unit 4 allow students to culminate their work, combining files and preparing it for presentation in the LMS game gallery.

Table 1 indicates the $\mathrm{N}$ of URLs in each of the curriculum units, and its contents. We aggregated page vies for the $\mathrm{N}$ of URLs under each unit, calculated aggregate page read totals in the given time increment, and then standardized the totals, dividing by $\mathrm{N}$ of students.

\subsection{Game Evaluation Outcomes, Dataset 2}

In order to evaluate students' game design outcomes, we adapted a content analysis approach to students' final game artifacts, but instead of considering commercial design implications, we consider the implications of the coded game artifact files for student learning. We applied Walker \& Shelton's [29] general coding strategy of measuring presence or absence of the variables $(1=$ Yes, $0=\mathrm{No})$ for our evaluation of a set of ActionScripts' inclusion in student games. We also followed Rourke and Anderson's [30] five steps to developing a theoretically valid scheme. We define "game" as: a file that goes beyond a mere image, to include some level of interactivity, in which, at minimum, the file provides response to the player, based on a player action. To be evaluated, files must reflect at least an actionable button and response screen, or an object that moves based on player actions. Distinguishing and defining a "game" at this most minimal level of interactivity allows us to code the full range of game files created by students, basic to advanced, and analyze the data based on this variability.

The final coding scheme enables evaluation of ActionScript programming codes that could reasonably be expected from introductory game design students ( 1 =present, $0=$ absent), and evaluation of design attributes built into the game (visual and sound design elements, game play experience, concept development, genre) ( $1=$ Not present / insufficient representation; 2=basic / introductory representation; 3=welldeveloped representation). The highest possible score was 61. The lowest possible score was 16. After several rounds of practice coding during coding development [30], inter-coder reliability was 
conducted on 26 student games created in 2012/2013 (out of $\sim 268$ games in total). To establish reliability, after our initial testing phase of the coding scheme, we trained a $\mathrm{PhD}$ student coder and a master's level coder, discussing and establishing best process for analyzing Flash code to ensure that code on both frame layers and movie clip objects were taken into consideration. The 26 games were then coded by one of the authors and a PhD student. Inter-rater reliability analysis using the Kappa statistic was conducted to determine consistency among raters. We performed the analysis for each section of the coding scheme. Results are presented separately for each game evaluation section below. The results for game evaluation provide an additive sum of the scores for all sections of the coding scheme.

- ActionScript programming evaluation. Kappa = 0.85 ( $<<.0 .001), 95 \%$ CI $(0.793,0.903)$.

- Visual and sound design evaluation. Kappa = 0.81 ( $\mathrm{p}<.0 .001), 95 \%$ CI $(0.725,0.894)$.

- Game play experience evaluation. Kappa $=0.87(\mathrm{p}$ $<.0 .001), 95 \%$ CI $(0.775,0.955)$.

- Concept development evaluation. Kappa $=0.75(\mathrm{p}$ $<.0 .001), 95 \%$ CI $(0.658,0.846)$.

\section{Results}

4.1. RQ1, variation in student uses of LMS resources by type, by school, and across time

Table 2 presents an overview of the descriptive statistics for the number of students, number of games, and average game quality score (maximum possible score $=61)$. Standard deviations indicate variation among schools for average game evaluation scores.

Table 2. Descriptive Statistics, General ( $N=20$ schools, students $=488$, games $=207$ )

\begin{tabular}{lllll}
\hline & Min & Max & Mean & Std. Dev. \\
\hline Students/school & 2 & 56 & 24.40 & 18.55 \\
Games/school & 1 & 41 & 10.35 & 9.65 \\
Team game eval. & 20 & 45 & 34.08 & 7.70
\end{tabular}
score (out of 61)

Descriptive statistics in Table 3 indicate the means and standard deviations for resource uses for curriculum pages (Intro, Units 1-4, ActionScript tutorials) and student editable pages (Profile, Project, Team pages) across the 5 timeframes (T1-T5).

Descriptive data shows that for Intro, Unit 1 and Unit 2, on average, students engaged in more resource uses in the earlier timeframes. While students engaged less frequently in use of Units 3 and 4 overall, their uses in aggregate appear to have occurred more in the latter timeframes. ActionScript tutorials comprised a broad array of resources and their uses occurred across all timeframes. For the student editable pages, Profile page views appeared higher in the earlier timeframes as would be expected when students set up their initial online identity, whereas Project page views appeared higher in the latter timeframes. Team pages were

Table 3. Resource Uses across 5 timeframes (standardized page views) ( $\mathrm{N}=20$ schools)

\begin{tabular}{|c|c|c|c|c|}
\hline $\begin{array}{l}\text { Curriculum } \\
\text { resource }\end{array}$ & Min & Max & Mean & $\begin{array}{l}\text { Std. } \\
\text { Deviation }\end{array}$ \\
\hline Intro T1 & 3.8 & 163.5 & 92.7 & 37.3 \\
\hline Intro $\mathrm{T} 2$ & 2.8 & 199.4 & 77.9 & 44.9 \\
\hline Intro $\mathrm{T} 3$ & 15.6 & 130.6 & 62.6 & 31.9 \\
\hline Intro $\mathrm{T} 4$ & 6.0 & 207.3 & 79.9 & 54.1 \\
\hline Intro T5 & 12.6 & 132.1 & 64.5 & 33.9 \\
\hline Unit $1 \mathrm{~T} 1$ & 1.5 & 61.8 & 17.2 & 14.4 \\
\hline Unit $1 \mathrm{~T} 2$ & 0.0 & 5.0 & 1.3 & 1.7 \\
\hline Unit $1 \mathrm{~T} 3$ & 0.0 & 29.0 & 3.0 & 6.9 \\
\hline Unit $1 \mathrm{~T} 4$ & 0.0 & 22.9 & 2.5 & 5.5 \\
\hline Unit 1 T5 & 0.0 & 0.5 & 0.2 & 0.2 \\
\hline Unit $2 \mathrm{~T} 1$ & 1.6 & 38.9 & 16.8 & 10.3 \\
\hline Unit $2 \mathrm{~T} 2$ & 0.0 & 39.6 & 10.1 & 9.5 \\
\hline Unit $2 \mathrm{~T} 3$ & 0.3 & 29.0 & 4.7 & 7.5 \\
\hline Unit $2 \mathrm{~T} 4$ & 0.3 & 30.6 & 5.5 & 8.3 \\
\hline Unit 2 T5 & 0.0 & 3.8 & 1.0 & 0.9 \\
\hline Unit $3 \mathrm{~T} 1$ & 0.3 & 14.9 & 2.7 & 4.0 \\
\hline Unit $3 \mathrm{~T} 2$ & 0.0 & 45.0 & 9.2 & 11.4 \\
\hline Unit $3 \mathrm{~T} 3$ & 0.2 & 30.4 & 7.9 & 8.2 \\
\hline Unit 3 T4 & 0.9 & 49.6 & 12.8 & 13.5 \\
\hline Unit 3 T5 & 0.2 & 18.2 & 4.9 & 5.1 \\
\hline Unit $4 \mathrm{~T} 1$ & 0.0 & 4.0 & 0.3 & 0.9 \\
\hline Unit $4 \mathrm{~T} 2$ & 0.0 & 2.0 & 0.3 & 0.5 \\
\hline Unit $4 \mathrm{~T} 3$ & 0.0 & 6.4 & 0.5 & 1.4 \\
\hline Unit 4 T4 & 0.0 & 0.6 & 0.2 & 0.2 \\
\hline Unit $4 \mathrm{~T} 5$ & 0.0 & 10.5 & 1.0 & 2.3 \\
\hline AS Tutorials T1 & 1.3 & 342.2 & 186.3 & 97.9 \\
\hline AS Tutorials T2 & 1.8 & 380.1 & 124.6 & 90.6 \\
\hline AS Tutorials T3 & 19.6 & 273.0 & 98.6 & 64.4 \\
\hline AS Tutorials T4 & 18.9 & 261.7 & 116.2 & 74.5 \\
\hline AS Tutorials T5 & 10.0 & 196.8 & 76.5 & 46.3 \\
\hline Profile Pages T1 & 0.0 & 88.9 & 37.6 & 23.3 \\
\hline Profile Pages T2 & 0.0 & 90.9 & 45.9 & 26.8 \\
\hline Profile Pages T3 & 0.9 & 87.4 & 24.6 & 17.4 \\
\hline Profile Pages T4 & 4.0 & 119.8 & 37.8 & 37.5 \\
\hline Profile Pages T5 & 2.8 & 66.8 & 20.7 & 17.9 \\
\hline Project Pages T1 & 0.0 & 23.6 & 1.8 & 5.7 \\
\hline Project Pages T2 & 0.0 & 63.6 & 12.1 & 21.0 \\
\hline Project Pages T3 & 0.0 & 46.7 & 15.0 & 17.5 \\
\hline Project Pages T4 & 0.0 & 69.7 & 23.3 & 16.8 \\
\hline Project Pages T5 & 0.0 & 111.3 & 27.6 & 25.4 \\
\hline Team Pages T1 & 3.8 & 163.5 & 92.7 & 37.3 \\
\hline Team Pages T2 & 2.8 & 199.4 & 77.9 & 44.9 \\
\hline Team Pages T3 & 15.6 & 130.6 & 62.6 & 31.9 \\
\hline Team Pages T4 & 6.0 & 207.3 & 79.9 & 54.1 \\
\hline Team Pages T5 & 12.6 & 132.1 & 64.5 & 33.9 \\
\hline
\end{tabular}


utilized across the 5 timeframes. Standard deviations indicate variation among schools for all units.

These findings indicate (a) students on average engaged more in Units 1 and 2, and less on Unit 3 and 4 which relates to latter phases of the curriculum. The online uses of these latter Units showed less frequency, while students were working more intently in Flash; (b) while use of Unit 3 is lower than earlier Units, the use increases later in the year as would be expected and the same for Unit 4 (though at a low order of magnitude; (c) schools varied substantially in their uses, as reflected by large standard deviations

\section{2. $R Q 2$, relationships among resource uses and learning outcomes}

Bivariate analysis was conducted to investigate correlations among resource use page views and game quality scores. Note, these are averages at the school level of analysis with an $\mathrm{N}$ of 20 . While our dataset comprises page views for each curriculum unit at all 5 timeframes, in the bivariate analysis we decided to include data only for the timeframe with the highest frequency of engagement for any given resource. Thus, Table 4 presents the bivariate results for just these select highest-frequency timeframes as reported in Table 3 (in bold), most of which are parsimonious (that is, the later the timeframe and more advanced the unit, the higher the page views appeared). The exceptions were ActionScript Tutorials and Team pages. For ActionScript tutorials we selected T4 because it was expected that the page views engaged by students in $\mathrm{T} 1$ and T2 were due to use of the introductory tutorials for buttons, also included in the individual game design phase. For Team pages we chose T4 even though T1 appeared higher, for the same rationale; the team page uses early on were due to their setup during the earlier individual phase, prior to when the teamwork actually began. We did run the analyses for all units and timeframes - and we report notable "ad hoc results" from the full analysis below for other timeframes. Space limitations necessitated selective presentation.
4.2.1. Early curriculum units; profile, project, team pages. Bivariate findings indicate that overall, Intro page views were correlated with the greatest number of other curriculum variables. The more a school used Intro resources, the more they used most of the other resources. Unit 1 and Unit 2 were used most during T1-2; these unit page views, along with Intro, are all inter-correlated. Unit 1 and 2 page views were not associated with latter curriculum uses or social engagement pages. These resource use types were required by the teachers and curriculum, during the individual game design phase in T1 and T2. Intro page views showed a correlation with Profile page views; Unit 2 correlated with Team pages.

4.2.2. Latter curriculum units. Among latter curriculum units, used more so in T3-T5, Unit 3 and 4 were correlated, and Unit 3 was also correlated to Intro, Profile and Team pages and Actionscript tutorials. Unit 4 page views correlated to Profile, Project and Team page use. ActionScript tutorials were correlated to Unit 3, and quite strongly to Team page views as well. The correlations among latter curriculum unit resources and the social engagement pages is sensible given that in this teamwork phase, students participated in active Flash project creation developing game assets and artifacts that were required to be uploaded to Team pages by teachers. For the Actionscript tutorials, when this knowledge was applied, students created more advanced game artifacts, also to be uploaded to the Team page.

\subsubsection{Resource uses and outcomes.}

Just two resources were associated with game evaluation outcomes, in the selective table findings. Interestingly, Unit 1 page views were negatively correlated whereas Team page views showed a positive correlation. Unit 4 and Project page views almost reached significance at the .1 level. It appears that the more students viewed Unit 1, the less likely they were perhaps to advance to latter stages and create more complex games. Team pages, as the locus of student

Table 4 . Standardized Page Views X Game Score $(\mathbf{N}=20)$

\begin{tabular}{|c|c|c|c|c|c|c|c|c|c|c|}
\hline & $\begin{array}{l}\text { Ave Game } \\
\text { Score }\end{array}$ & $\begin{array}{l}\text { \% Free/ } \\
\text { Red. } \\
\text { Lunch }\end{array}$ & $\begin{array}{l}\text { Intro } \\
\text { PVs }\end{array}$ & $\begin{array}{l}\text { Unit } 1 \\
\text { PVs }\end{array}$ & $\begin{array}{l}\text { Unit } 2 \\
\text { PVs }\end{array}$ & $\begin{array}{l}\text { Unit } 3 \\
\text { PVs }\end{array}$ & $\begin{array}{l}\text { Unit } 4 \\
\text { PVs }\end{array}$ & $\begin{array}{l}\text { AScript } \\
\text { Tutorials }\end{array}$ & $\begin{array}{l}\text { Profile } \\
\text { PVs }\end{array}$ & $\begin{array}{l}\text { Project } \\
\text { PVs }\end{array}$ \\
\hline Avg. Game Score & 1 & & & & & & & & & \\
\hline$\%$ Free/Red. Lunch & -0.28 & 1 & & & & & & & & \\
\hline Intro PVs & 0.00 & -0.09 & 1 & & & & & & & \\
\hline Unit $1 \mathrm{PVs}$ & $-0.41^{*}$ & 0.12 & $0.38^{*}$ & 1 & & & & & & \\
\hline Unit 2 PVs & 0.15 & -0.31 & $0.46^{* *}$ & $0.46^{* *}$ & 1 & & & & & \\
\hline Unit 3 PVs & 0.13 & -0.13 & $0.37^{*}$ & 0.20 & 0.29 & 1 & & & & \\
\hline Unit 4 PVs & 0.33 & -0.30 & 0.20 & -0.09 & 0.33 & $0.65^{* * *}$ & 1 & & & \\
\hline AS Tutorial & 0.18 & -0.10 & $0.39^{*}$ & 0.03 & 0.09 & $0.40^{*}$ & 0.27 & 1 & & \\
\hline Profile PVs & 0.01 & -0.11 & $0.78^{* * *}$ & 0.35 & 0.34 & $0.48^{* * *}$ & $0.39^{*}$ & 0.47 & 1 & \\
\hline Project PVs & 0.37 & -0.22 & 0.03 & -0.24 & 0.20 & 0.27 & $0.60^{* * *}$ & -0.03 & 0.29 & 1 \\
\hline Team PVs & $0.39^{*}$ & -0.19 & $0.51^{* *}$ & 0.06 & $0.29^{*}$ & $0.53^{* *}$ & $0.66^{* * *}$ & $0.52^{* * *}$ & $0.47^{*}$ & 0.09 \\
\hline
\end{tabular}

${ }^{*}$ Correlation is significant at the 0.1 level (2-tailed)

** Correlation is significant at the 0.05 level (2-tailed)

${ }^{* * *}$ Correlation is significant at the 0.01 level (2-tailed) 
constructive, creative design productivity, is parsimonious as a correlate to measured outcomes.

Overall, apparent resource use activity factors emerged among (a) student/school uses of Intro, Unit 1, Unit 2, Profile and Team page views, and (b) Units 3, 4, ActionScript Tutorials, Project and Team pages. While the overall volume of page views for Units 3 and 4 appeared substantially lower (earlier Table 3), we still had enough variation to see significance for these units, that are partially explainable given what we know about types of activities occurring during the early individual work $(\mathrm{T} 1, \mathrm{~T} 2)$ or later teamwork (T3T5). These two apparent factors indicate that students/schools who reached latter curriculum phases may have been rather different from those who used the more advanced resources.

\subsection{Ad hoc results, additional findings on resource uses and outcomes.}

Recall that the decision was made to analyze only the resource use timeframe with the highest mean page views for any given resource type (e.g., Unit 3, T4). To fully consider the relationships across timeframes, and especially with regard to student game quality outcomes, notable ad-hoc results are now presented for the rest of the timeframes. Findings indicate several more positive and statistically significant relationships between resource use types and game evaluation outcome scores:

- Intro, T5 $(R=.52, \underline{p}<.05)$

- Unit 3, T2 $(R=.45, p<.05)$

- Unit 4, T4 and T5 were close to significant for $p<.1$

- AS Tutorials, T3 \& T5 $(R=.38, p<.05 ; R=.38, p<.1)$

- Profile pages, T5 $(R=.45, \underline{p}<.05)$

- Team pages, T2 through T5 $(R=.59, p<.01 ; R=.57$, $p<.01, R=.39, p<.1 ; R=.51, p<.05)$.

Intro was the most commonly used unit across time. The result for T5 was likely due to Intro including the homepage, and game gallery which students visited to review past games while refining and polishing their final products. Results for Unit 3 in T2 show that the more students arrived at this advanced stage earlier on, the better the outcomes. Unit 3, 4, AS Tutorials and Team page findings lend support to the utility of the information resources provided in these more advanced units, for those students who are able to find and use them in the latter stages of game design.

\section{Discussion}

Guided discovery-based e-learning platform approaches to CS education are growing in interest among scholars and practitioners in the field, in part due to teacher shortages at the K-12 in this domain. The challenge of heeding the call of national education technology policy agendas such as the Obama administration's "CS4All" initiative have quickly become evident to CS education experts, as the field reconciles the practicalities of in-school implementation. Reliance upon online learning systems populated with expert authoritative resources for CS education, delivered as a fully intact curriculum for blended e-learning (or distance learning), may be one of the few workable short-term to mid-term solutions.

\subsection{Student uses of system affordances.}

5.1.1. Information resources. Information resources were provided across learning units to facilitate students' guided discovery-based learning. Findings for curricular unit page views indicate that students engage more so with units earlier in curriculum (Intro, Unit 1, Unit 2) than later (Units 3, 4). These uses appear to fall in two activity factors, in that inter-relationships do not exist between them, only among the units within each set. Students are more directly immersed in the parallel activity of software programming use during T3-5, and time spent on the LMS was thus more minimal. Thus, it appears that uses of the Unit 3 and Unit 4 resources were more directed, towards problem-solving programming issues for their team game during latter phases, and frequencies lower.

The earlier set offers a common denominator of resources that can be used broadly by all, whereas the latter units are more advanced, challenging, less frequently utilized. Frequency of the initial set's use does not predict engagement with more advanced material, or learning outcomes. Of note, the game evaluation was conducted on the team game artifacts, thus we might expect these results given that units 3 and 4 involved activity more contingent with the object of evaluation. More nuanced evaluation might evidence cumulative learning effects of the earlier phase individual resource uses, upon latter teamwork phases and outcomes.

The negative correlation for Unit 1 upon outcomes could be due to the small $\mathrm{N}$ of schools where students spent more time on this earlier phase, resulting in less advancement and lower game complexity. Latter units showed associations with outcomes as did ActionScript tutorials, as evidenced in the ad hoc results.

5.1.2. Social features. The Project and Team pages are the locus for coordinating students' active design and programming work, where they archive, present and share their game file assets and code. Uses reflect iterative game construction and communicating about game design through artifact sharing, reviewing, meaning-making (augmented by in-class discussion in teams). Findings indicate that students visited Profile pages and Team pages more so than Project pages; the Project pages are used in T1-2. Team page views contribute to outcomes across T2-T5. These uses provide evidence supporting the social constructivist, 
guided inquiry approaches underscoring Globaloria, and LMS's role as "coordinating representation." [27]

5.1.3. Knowledge-building. The findings in this study support three out of 12 principles in Scardamalia's knowledge-building model: epistemic agency, constructive uses of authoritative sources, and knowledge-building discourse [22]. The Google Analytics data offered us a lens into resource uses during 2 phases of learning (individual and teamwork phases) in which at first individual agency was needed, followed by more collaborative teamwork processes requiring of individual agency-within-teams. Further, the student work was supported by pre-scaffolded teamwork-based activities to cultivate social constructivist engagement, along with system affordance of the Team page, designed to foster online collaboration and sharing. Team page views reflected the compiled activity of edits, uploads and views, in aggregate. Game design artifacts that students post serve as a form of discourse through the ongoing layering in of digital artifacts, each asset imbued with a host of complex meanings. The frequency and outcome findings for team pages show that such discourse is occurring, and contributes to outcomes. As for authoritative resource uses, variation in game quality is statistically associated to uses of more expert resources; when they use them, they do better; not all schools/students get there, though.

5.1.4. Information literacy. On the whole, the curriculum does not offer extensive support for information literacy as a deliberate task, a result noted in prior research as an area for development [28]. A greater breadth and depth of student resource uses may occur if the program offered scaffolds for information literacy as a domain of expertise. This might include for instance, offering heuristics for greater intuitive knowing when an information need or gap surfaces, what to do when this occurs, identification of appropriate resource supports, initiating search process, improved understanding of the LMS navigation and resources, and supporting students' resilience to persevere in inquiry. The findings invite research on the application and testing of information literacy scaffolds with students and teachers.

5.1.5. Limitations. While such LMS-generated behavioral site metrics data shed light on resource use patterns, such data have limitations in the insights they may offer. In addition to the limitations and need for further research with regard to levels of analysis, we also noted the following observations during case study site visits, possibly affecting page views. (1) Low frequencies for site resources may belie significant productive activity in class, not lack of utility of resources. (2) On (rare) occasions, students log in to the LMS as a user other than themselves, and/or share computers without changing the login credentials. This doesn't affect school-level findings but is for future note in multi-level research. (3) Outliers such as single individuals or teams are obscured in the aggregate page views. These and other limitations must be considered in the work moving forward.

5.1.6. Future work: Role of teachers, using levels of analysis. The variation across schools and classrooms suggests teachers differ in how their students participate. While the individual and team level of analysis may be playing a role in school-level aggregate variations, class management and instructional differences among teachers also play a role. All of these factors may influence the extent of "resourcefulness" students and teams evidence in using resources to support their learning, and thus, why schools may show such variation as we see here. For instance, Reynolds \& Chiu [31, 32] used multi-level analysis modeling to report upon results from two large $\mathrm{N}$ survey datasets in two other school years, showing that in addition to school-level differences such as those we see here, individual and team differences also play a role in various outcomes, including changes in student technology use dispositions, and knowledge. Reynolds [28] also finds that team dynamics influence resource uses and such differences appear to contribute outcomes. Adding teacher-level data, for instance on teacher information literacy skills, dispositions, and game design expertise, will offer important insights as to how much of a role individual teachers really do play, when guided discovery-based e-learning for CS education is delivered. The teacher factor is key for the field to address when considering guided discovery as a possible pragmatic solution to for CS education in K12 moving forward. Adding teacher-level variables in future multi-level analysis research is intended.

This study investigated a model implementation for blended e-learning, considering the ways in which Google Analytics site metrics data and learning outcomes data can be combined to show patterns of instructional effectiveness during students' guided discovery. The study aims to contribute to the evidence base addressing the effectiveness of such models. The study also offers recommendations for instructional designers, for features enhancements including information literacy scaffolds, as such blended instruction $\mathrm{CS}$ education contexts in $\mathrm{K}-12$, begin to scale.

\section{References}

[1] Wilson, C., Sudol, L., Stephenson, C., and Stehlik, M., "Running on empty: The failure to teach K-12 computer science in the digital age", ACM Report, 2010, retrieved from http://csta.acm.org/runningonempty/fullreport.pdf. Accessed February, 2015. 
[2] Office of the Press Secretary, The White House, "Fact Sheet: President Obama announces Computer Science for All Initiative"

[3] Harel Caperton, I., "Toward a theory of game-media literacy: Playing and building as reading and writing", International Journal of Gaming and Computer-Mediated Simulations, 2(1), 2010, pp. 1-16.

[4] Reppening, A., Webb, D., and Ioannidou, A., "Scalable game design and the development of a checklist for getting computational thinking into public schools", The 41st ACM Technical Symposium on Computer Science Education, ACM Press, Milwaukee, WI, 2010.

[5] Grover, S. and Pea, R.D., "Computational thinking in K12: A review of the state of the field", Educational Researcher, 42(1), 2013, pp. 38-43.

[6] Dahlstrom, E., de Boor, T., Grunwald, P., Vockley, M., The ECAR National Study of Undergraduate Students and Information Technology, EDUCAUSE, Boulder, CO, 2011.

[7] Krumm, A.E., Waddington, R.J., Teasley, S.D., and Lonn, S., "A learning management system-based early warning system for academic advising in undergraduate engineering", in J.A. Larusson and B. White (eds.), Learning Analytics: From Research to Practice, Springer, New York, 2014, pp. 103-119.

[8] Siemens, G. and Long, P., "Penetrating the fog: Analytics in learning and education", EDUCAUSE Review, 46(5), 2011, pp. 30-32.

[9] Macfadyen, L.P. and Dawson, S., "Mining LMS data to develop an 'early warning system' for educators: A proof of concept", Computers \& Education, 54(2), 2010, p. 588-599.

[10] Salen, K, Torres, R, Rufo-Tepper, R, Shapiro, A, and Wolozin, L., "Quest to Learn: Growing a school for digital kids", MIT Press, Cambridge, MA, 2010.

[11] Kafai, Y.B. and Ching, C.C., "Children as instructional designers: Principles of learning with guided discoveries", in N.M. Seel and S. Dijkstra (Eds.), Curriculum, plans, and processes in instructional design: International perspectives, Lawrence Erlbaum Assoc., Mahwah, NJ, 2004, p. 115-130.

[12] Peppler, K. and Kafai, Y., "From SuperGoo to Scratch: exploring creative digital media production in informal learning", Learning, Media, and Technology, 32(2), 2007.

[13] Hmelo-Silver, C.E., Duncan, R.G., and Chinn, C.A., "Scaffolding and achievement in problem-based and inquiry learning: A response to Kirschner, Sweller, and Clark (2006)", Educational Psychologist, 42, 2007, pp. 99-107.

[14] Kirschner, P.A., Sweller, J., and Clark, R.E., "Why minimal guidance during instruction does not work: An analysis of the failure of constructivist, discovery, problembased, experiential, and inquiry-based teaching", Educational Psychologist, 41, 2006, pp. 75-86.

[15] Reese, D. D.,"Affect during instructional video game learning", in S. Tettegah \& W. D. Huang (Eds.), Emotion, technology, and games, Elsevier, New York, in press.

[16] Norris, C. and Soloway, E., "The 10 barriers to technology adoption" District Administration, Nov, 2011.

[17] Vygotsky, LS., Thought and language, MIT Press, Cambridge, MA, 1962.

[18] Papert, S., and Harel, I. (eds.), Constructionism, Ablex Publishing, Norwood, NJ, 1991.
[19] diSessa, A. and Cobb, P., "Ontological innovation and the role of theory in design experiments", Journal of the Learning Sciences, 13(1), 2004, pp. 77-103.

[20] Barron, B. and Darling-Hammond, L., "Teaching for meaningful learning: A review of research on inquiry-based and cooperative learning", 2008, Edutopia, retrieved from http://www .edutopia.org/pdfs/edutopia-teaching-formeaningful-learning.pdf. Accessed June 2016.

[21] Stager, G., "Computationally-rich constructionism and at-risk learners", paper presented at the 2001 World Conference on Computers in Education, Copenhagen, Denmark, 2001, retrieved from http://www.stager.org/wcce/index.html.

[22] Scardamalia, M., "Collective cognitive responsibility for the advancement of knowledge", in B. Smith (ed.), Liberal Education in a Knowledge Society, Open Court, Chicago, 2002, pp. 67-98.

[23] Chan, C. K., "Collaborative knowledge building: Towards a knowledge creation perspective", In C. E. HmeloSilver, C. A. Chinn, C. K. K., Chan and A. M. O'Donnell, (eds.), International Handbook of Collaborative Learning, New York, Taylor and Francis, 2013, pp. 437-461.

[24] Van Aalst, J., "Distinguishing knowledge-sharing, knowledge-construction, and knowledge-creation discourses", International Journal of Computer-Supported Collaborative Learning, 4(3), 2009, pp. 259-287.

[25] Reynolds, R. and Hmelo-Silver, C., "Areas of theoretical convergence in the Globaloria game design initiative: Constructionism, knowledge building and guided discovery based learning", paper presented at American Education Research Association , April 2013, p. 26-29.

[26] Salomon, G., Perkins, D., and Globerson, T., "Partners in cognition: Extending human intelligence with intelligent technologies", Educational Researcher, April 1991, pp. 2-9.

[27] Larusson, J.A. and Alterman, R., "Wikis to support the "collaborative" part of collaborative learning", ComputerSupported Collaborative Learning, 4, 2009, pp. 371-402.

[28] Reynolds, R. (2016). Relationships among tasks, collaborative inquiry processes, inquiry resolutions, and knowledge outcomes in adolescents during guided discoverybased game design in school. Journal of Information Science: Special Issue on Searching as Learning. 42, 35-58.

[29] Walker, A. and Shelton, B. E., "Problem-based educational games: Connections, prescriptions, and assessment", Journal of Interactive Learning Research, 19(4), 2008, pp. 663-684.

[30] Rourke, L. and Anderson, T., "Validity in Quantitative Content Analysis," Educational Technology Research and Development, 52(1), 2004, pp. 5-18.

[31] Reynolds, R., and Chiu, M. "Contribution of motivational orientations to student outcomes in a discoverybased program of game design learning." Proceedings of the International Conference of the Learning Sciences (ICLS) conference, July 2012, Sydney, Australia.

[32] Reynolds, R. and Chiu, M. "Reducing digital divide effects through student engagement in coordinated game design, online resource uses, and social computing activities in school." Journal of the Association for Information Science and Technology. 2015, 67(8), pp.1822-1835. 